\title{
Uma ética do comum(ista)
}

\author{
Commonist Ethics
}

\author{
Autora: Susan Buck-Morss \\ Professora no departamento de Ciência Política na \\ CUNY Graduate Center \\ Tradução: Régis Alves \\ Doutorando em filosofia pela USP \\ Revisão Técnica: Lucas Machado \\ Doutorando em filosofia pela USP
}

1.

Drimeiro ponto: a política não é uma ontologia. A afirmação - de que o político é sempre ontológico precisa ser contestada [1]. Não é que simplesmente a afirmação negativa seja o caso - que o político nunca seja ontológico [2] (como aponta Badiou, uma simples negação deixa tudo em seu lugar [3]). Em vez disso, o que é necessário é uma inversão da negação: o ontológico nunca é político.

Disto segue-se que o movimento de la politique (a política cotidiana) para le politique (o significado próprio do político) 
é uma via de mão única. Com todo o respeito a Marcel Gauchet, Chantal Mouffe, Giorgio Agamben e a muitos outros, a tentativa de descobrir dentro da vida política empírica (la politique) a essência ontológica do político (le politique) leva a teoria a um impasse, a partir do qual não há retorno à prática política real. Não se ganha nada com este movimento do feminino para o masculino. O projeto pós-metafísico de descobrir a verdade ontológica no interior da existência vivida fracassa no âmbito político. Ele fracassa no modo Husserliano-Heideggeriano, socialmente desengajado, de colocar entre parênteses o existenziell para descobrir a natureza essencial do que é "o político". E fracassa com o método socialmente crítico, pós-foucaultiano, da ontologia historicizada, que revela as múltiplas formas de politicamente ser-no-mundo dentro de configurações culturais e temporais particulares.

Isso não é novidade. A partir de meados da década de 1930, a preocupação obsessiva de Adorno, no contexto da ascensão do fascismo, foi demonstrar o fracasso da tentativa ontológica de fundamentar uma filosofia do Ser a partir do mundo dado - ou, na linguagem heideggeriana, passar do ôntico, ou seja, do ser [seiend] no sentido daquilo que é empiricamente dado, ao ontológico, àquilo que é essencialmente verdadeiro da existência (Dasein como a "estrutura a priori" da "existencialidade" [4]). Adorno argumentava que qualquer ontologia derivada (ou reduzida [5]) do ôntico transforma o projeto filosófico em uma grande tautologia [6]. Não lhe faltava razão, e as implicações políticas são sérias.

A ontologia identifica. A identidade era um anátema para Adorno, sobretudo no campo de suas implicações políticas - a identidade entre governante e governado afirmada pelo fascismo. Certamente, mesmo o governo parlamentar parece pressupor uma luta por identidade, na qual o consenso se torna um fim em si mesmo, a despeito do conteúdo de verdade desse consenso [7]. Não é que a filosofia de Heidegger (ou qualquer ontologia existencial) seja em si mesma fascista (esta seria uma afirmação ontológica). O que se passa é que, ao resolver a questão do Ser antes das análises políticas subsequentes, as últimas 
não têm força filosófica. Elas são subsumidas sob os a prioris ontológicos que devem permanecer indiferentes ao seu conteúdo [8]. A ontologia existencial está equivocada ao assumir que, uma vez que "o caráter do ser" (Heidegger) é conceitualmente apreendido, este nos devolverá ao mundo material, empírico, e nos permitirá reunir suas diversidades e multiplicidades sob as compreensões de antemão próprias da filosofia de maneira adequada às exigências da ação coletiva, às demandas da vida política real. De fato, o ontológico nunca é político. Uma ontologia do comum (ou comunista) é uma contradição em termos.

Mas, alguém poderia perguntar: o próprio Marx não esboçou em seus primeiros escritos uma ontologia inteira baseada na clássica afirmação aristotélica de que o homem é por natureza um animal social? Os manuscritos de 1844 não são uma elaboração dessa afirmação, mediada por uma crítica historicamente específica, portanto, uma ontologia social expandida da alienação do homem em relação à natureza (incluindo a sua) e aos seus semelhantes? Sim, mas na vida real, política, esse "homem" ontológico não existe.

Em vez disso, nós, criaturas existentes, somos homens e mulheres, negros e pardos, capitalistas e trabalhadores, gays e heterossexuais, e o significado dessas categorias do ser não é, de maneira alguma, estável. Além disso, essas diferenças são menos importantes do que se estamos desempregados, temos antecedentes criminais ou corremos o risco de ser deportados. $\mathrm{E}$, independentemente do que nós somos nesses modos ônticos, nosso ser não se encaixa perfeitamente em nossas opções políticas, sejamos conservadores, anarquistas, evangélicos, partidários do Tea Party, sionistas, islamitas e (alguns) comunistas. Nós somos animais sociais, sim, mas também somos anti-sociais, e nossa natureza animal é completamente mediada pelas formas contingentes da sociedade. Sim, o primeiro Marx desenvolveu uma ontologia filosófica. Politicamente, nada se segue disso. A ditadura do proletariado não é assim legitimada, e toda a questão espinhosa da falsa consciência (consciência empírica vs. imputada / atribuída [zugerechnetes [Bewußtsein]]) não pode por isso ser resolvida. Ao mesmo tempo, o pensamento filosó- 
fico tem todo o direito - e obrigação - de intervir ativamente na vida política. Aqui temos Marx tratando do tema da prática intelectual, incluindo a filosófica:

Posto que também sou cientificamente ativo etc., uma atividade que raramente posso realizar em comunidade imediata com outros, então sou ativo socialmente porque [o sou] enquanto homem. Não apenas o material da minha atividade como a própria língua na qual o pensador é ativo - me é dado como produto social, a minha própria existência é atividade social; por isso, o que faço a partir de mim, faço a partir de mim para a sociedade, e com a consciência de mim mesmo como um ser social [9].

Novamente, não importa o quão profundamente alguém pense sobre esta generalização ontológica, desta não se segue nenhuma orientação política específica como consequência. Ela descreve o trabalho intelectual de Heidegger e Schmitt tanto quanto o de Marx ou de nós mesmos.

Para Marx, a filosofia ontológica era apenas o ponto de partida de uma prática vitalícia de pensamento científico que se desenvolveu em resposta aos acontecimentos históricos que o cercavam. Por meio da trajetória de sua obra, toda a tradição da filosofia política ocidental deu uma virada à esquerda que a afastou da metafísica e a encaminhou para um engajamento com as ciências sociais emergentes - economia, antropologia, sociologia, psicologia -, entendidas não em sua forma positivista, coletora de dados ou abstrato-matemáticas, mas como ciências da história; não historicalidade, historicidade, historicismo e similares, mas história concreta, material. Com essa acentuada virada à esquerda (que é uma orientação que pode ou não envolver elementos da "virada linguística", "virada ética", "virada estética"), a filosofia política se transforma em teoria social feita reflexivamente, ou seja, criticamente. Torna-se teoria crítica.

Quando Marx disse que o pensamento era ele mesmo uma prática, o dizia nesse sentido. Ele não se perguntou então: qual é o significado ontológico do ser da prática. Em vez disso, ele tentou descobrir o máximo possível sobre as práticas sócio-históricas dos seres humanos reais de seu tempo. 
Portanto, a questão que nos deixa os primeiros escritos de Marx é a seguinte: como podemos transformar esse fato social - poderíamos dizer, de maneira descritiva, socialista - de nosso trabalho, e nossa consciência desse trabalho como seres sociais, em uma prática do comum? Como devemos conceber uma ética do comum? Não pela redução fenomenológica a algum tipo de essência do que é ser um ser social: por exemplo, o ser que cuida, o ser-para-a-morte, o ser-com, e etc., como Heidegger propôs, mas sim, por meio de uma análise, um tornar-se consciente da sociedade específica, dos cuidados específicos, das mortes específicas que são simultâneas à nossa; não comuns no sentido de serem iguais a nossa (as experiências são muito desiguais na sociedade de hoje), mas no de que acontecem a outros que compartilham, que têm em comum, este tempo e este espaço - um espaço tão grande quanto o globo e um tempo tão atual quanto o presente.

\section{2.}

Marx mudou a relação entre política e filosofia ao criar uma articulação a partir das ciências sociais. Esta articulação se desgastou. As ciências sociais de hoje, filosoficamente ingênuas, pretendem ser objetivas à medida que dividem a realidade em disciplinas acadêmicas autorreferentes que argumentam a partir dos "dados" atuais como uma base quase natural (em vez de estruturas instáveis e dinâmicas que dependem da ação humana). De sua parte, a filosofia, sozinha, refugia-se nas humanidades: no pensamento normativo, em uma análise da razão e no mundo kantiano dos deveres morais, ou, alternativamente, em um anti-racionalismo inspirado em Nietzsche, na celebração do afeto, no relativismo cultural, na narratividade literária, na contingência hermenêutica. Até mesmo a filosofia crítica compartilha com as ciências positivistas das quais se separou a suposição de que pode conhecer a realidade por conta própria. Ambas as abordagens - pensamento sem entendimento empírico e entendimento empírico sem pensamento, sem reflexão crítica - são extremamente suscetíveis à reificação. 
Enquanto isso, o marxismo, órfão de ambas as partes do projeto acadêmico, das ciências e das humanidades, corre o perigo de incorrer em dogmatismo caso pretenda fornecer um conhecimento de antemão (a priori) do significado político dos acontecimentos com base em textos centenários, encaixando todo fato empírico em seu quadro interpretativo preexistente. Como código mestre da história, o marxismo concede a um sistema capitalista antropomorfizado uma agência todo-poderosa. O capitalismo é o mentor dos acontecimentos, explora vorazmente em vista de ganhos privados e deleita-se com a crise, ao mesmo tempo que frustra nossas melhores intenções morais, determinando resultados históricos com uma perspicácia muito maior do que qualquer astúcia hegeliana da razão poderia proporcionar.

Como todos sabem, Marx usou o termo capitalismo apenas um punhado de vezes. O grande livro é chamado $O$ Capital. E é uma exposição crítica das práticas econômicas de seu tempo, incluindo os processos de fetichismo e reificação, que fazem as leis do capital aparecer como nosso destino necessário.

Agora farei uma defesa tediosa: devido às consequências epistemológicas, devemos rejeitar a criação de um "-ismo" a partir de qualquer orientação política ou teórica. Nada de comunismo, capitalismo, marxismo, totalitarismo ou imperialismo; absolutamente nenhum “-ismo" [10]. Esses são sistemas cosmológicos, economias de crença que se assemelham à economia cristológica medieval (oikonomia), em que todos os elementos são internamente consistentes e logicamente satisfatórios, desde que não haja contaminação por fatos ou eventos que, oriundos de fora, penetrem em suas fronteiras como algum tipo de estrangeiro ilegal. Com as simples palavras - comunista ou socialista, capitalista ou marxista, e etc., se passa outra coisa. Se são usadas apenas como adjetivos descritivos, elas se referem a qualidades (determinações) de objetos no mundo por elas definidos; objetos que, se quisermos ser materialistas consequentes, devem ter prioridade sobre os conceitos que usamos para nomeá-los [11]. 
A prática política também é vulnerável à sedução do "-ismo". É um erro adotar o anarquismo ou o socialismo, o trotskismo ou o islamismo, o radicalismo ou o parlamentarismo, como um sistema de crenças que determina antecipadamente nossas ações. As condições mudam e a prática precisa responder a novas situações. Tomar o poder do Estado para controlar seus aparatos ideológicos? Sim, mas e se, após a transformação global do capital, o próprio Estado se tornar um aparato ideológico? Basear nossa política em um respeito anarquista pela agência democrática? Sem dúvida. Mas não se isso significar ceder às táticas manipuladoras do populismo de direita, cada vez mais difundidas.

Dizer, com Althusser, que Marx abandonou o humanismo de seus primeiros anos por uma "ciência da história" implica que a ciência marxista é trans-histórica e eterna, um primeiro princípio ontológico imune precisamente à especificidade histórica na qual ela insiste - como se a ciência não fosse ela mesma histórica. (Temos apenas que pensar nos limites históricos da ciência de Ricardo ou Malthus, ou, dada a atual crise, da Escola de Chicago de economia, para esclarecer esse ponto.) Defender, com Negri, uma "ontologia histórica" baseada em uma compreensão científica do processo de luta de classes capitalista é uma alternativa duvidosa. Negri quer adicionar uma dose de contingência histórica à mistura, ao mesmo tempo em que conta com uma dose de correção ontológica para evitar os perigos do relativismo que a contingência implica. Ele não deixa de lado a luta de classes como a prima philosophia, o primeiro princípio filosófico, sobre o qual se funda todo o projeto político. Mas se, pace Negri, não pode haver ontologia da história, é porque a história é o reino da liberdade humana e, portanto, o reino do imprevisível, tanto no pensamento quanto na prática. Nesse ponto, em vez de tentar desenvolver uma ontologia da liberdade, precisamos reconhecer a aparência surpreendente e fugaz da liberdade no mundo.

Eu estou revelando minha verdadeira postura. Eu sou uma pragmatista incorrigível quando se trata de teoria crítica. Mas não se trata de pragmatismo, no sentido de Rorty ou mesmo 
de Dewey (e não tem nada a ver com ser norte-americana). Minha posição está mais próxima do que Bertold Brecht descreveu (e admirou) como plumpes Denken - pensamento não-elegante. Assim, por exemplo, onde o filósofo elegante iria descobrir um conceito procurando o significado clássico de um termo grego, eu me inspiro no grego moderno, demotiki, a linguagem de rua do povo (demos), que, junto com a dita irresponsabilidade fiscal dos próprios gregos, é em grande medida desdenhada pela intelligentsia europeia. Ta pragmata em grego moderno refere-se às coisas práticas utilizadas na vida cotidiana. Em alemão: die Klamotten, no sentido das coisas que, por mais que possam parecer lixo para os outros, necessita-se e usa-se todos os dias.

Neste sentido, uma abordagem pragmática para a elaboração teórica fazer teoria possui uma semelhança com o comentário que o romancista nigeriano Wole Soyinka fez quando criticou a compreensão da nègritude como ontologia dizendo: "Um tigre não proclama sua tigritude: ataca". Posteriormente esclareceu: "um tigre não fica na floresta e diz: 'Eu sou um tigre'. Quando você passa por onde o tigre andou antes, você vê o esqueleto de um antílope e sabe que alguma tigritude irradiou ali" [12]. (Figuras 1 e 2)

Soyinka abandona a ontologia por algo próximo do que quero dizer com pragmática teórica [13]. É uma prática de teorizar por meio da qual as coisas adquirem significado por causa de sua relação prática, pragmática com outras coisas, e na qual essas relações estão permanentemente abertas, permanentemente precárias. Seu futuro não pode ser previsto com antecedência. 


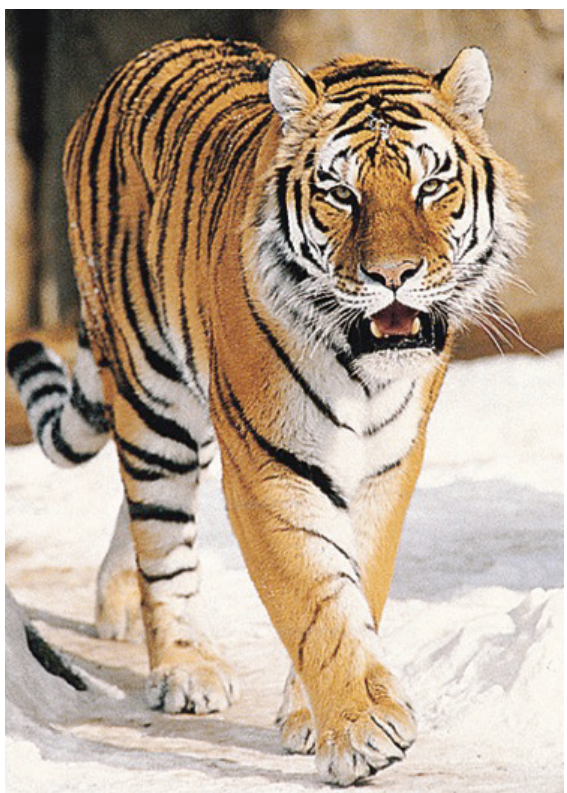

Fig. 1

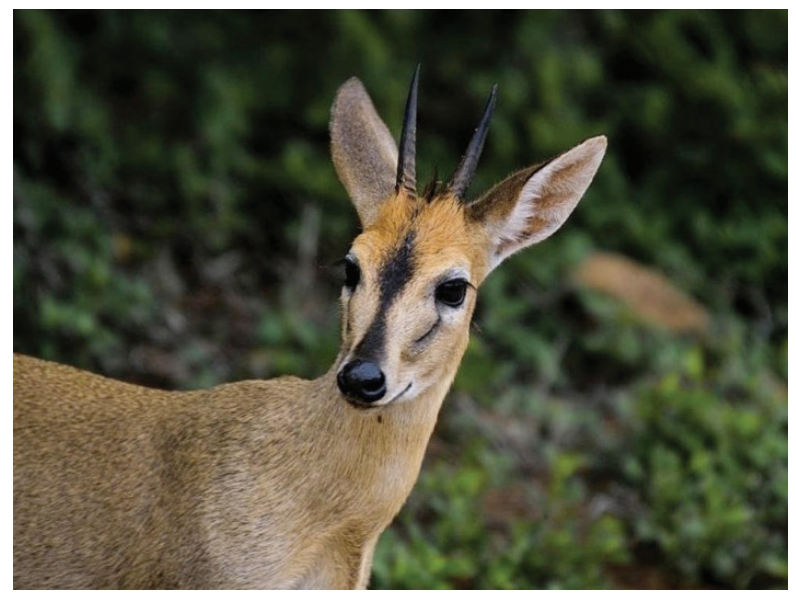

Fig. 2 - Duiker (em inglês) é um pequeno antílope. 
Agora, se estivéssemos interessados apenas na ciência empírica da prática do tigre, seríamos behavioristas, observando de uma distância segura o que um tigre faz. Mas enquanto atores políticos no meio das coisas, somos antílopes, e os antílopes precisam estar a par das últimas notícias.

Podemos imaginar Lênin sem um jornal? (Figura 7) Ou Marx, ou Hegel? Marx escreveu para jornais sobre eventos distantes da Europa - o colonialismo na Índia, o comércio na China, a Guerra Civil dos EUA. E Hegel estava formulando a dialética do senhor e do escravo por causa das notícias sobre a Revolução Haitiana que ele leu em sucessivas edições do periódico político Minerva.

Lênin, vamos lembrar, não esperava que a revolução ocorresse a) na Rússia , ou b) no verão, ou mesmo no outono, de 1917. Mas ele permitiu que sua teoria se adaptasse aos desenvolvimentos históricos tal como realmente ocorreram [14]. O acontecimento histórico que surpreende: esta é a "realidade radical" à qual Lenin permaneceu aberto [15]. Aqui estou em total concordância com Badiou em relação à centralidade política do acontecimento, e na mesma página que ele, quando enfatiza "a absoluta imprevisibilidade do evento" que "pode ser a fonte de surgimento do radicalmente novo" [16]. Mas eu tomaria liberdades com a formulação de Lacan que Badiou não toma. Não é a "verdade" que "abre um buraco no conhecimento". Mas sim, uma ação social. E a verdade que tal ação revela é a possibilidade da liberdade humana. Então, se juntarmos a ideia de pragmática e a ideia de acontecimento, teremos uma pragmática do subitamente possível como expressão da liberdade humana. E esta não é uma má definição do que implicaria uma ética do comum.

Portanto, falando na linguagem deselegante do plumpes Denken, as questões de caráter filosófico que uma pragmática do subitamente possível precisaria perguntar são estas: 
1. O que está acontecendo? (A alternativa pragmática à "ontologia histórica")

2. O que há de novo? (Existe um "acontecimento" ocorrendo aqui?)

3. O que produz? (Que estruturas de poder estão subitamente cedendo aos atores no acontecimento)

4. O que permanece? (Há certas estruturas que NÃO estão em processo de mudança?)

E só então chegamos à Grande Questão:

5. O que fazer? ("O que deve ser feito?" é a tradução errada de Что делать?).

Talvez devamos nos deter por um momento sobre essas questões para visualizá-las a partir da perspectiva do comum.

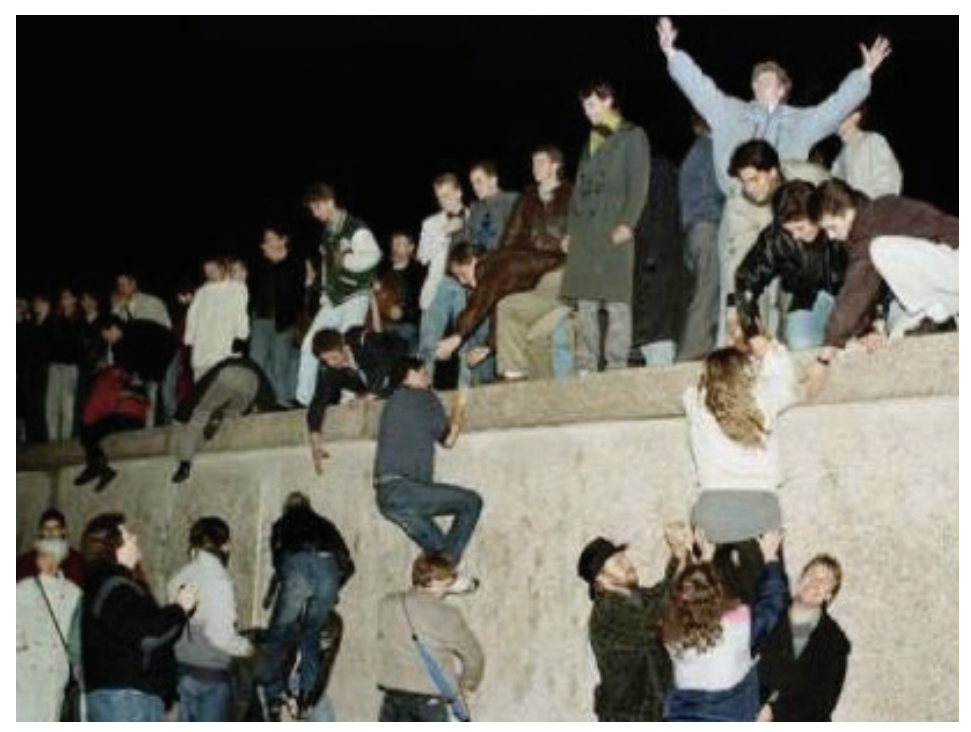

Fig. 3 - Queda do Muro de Berlim, 9 de novembro de 1989. 


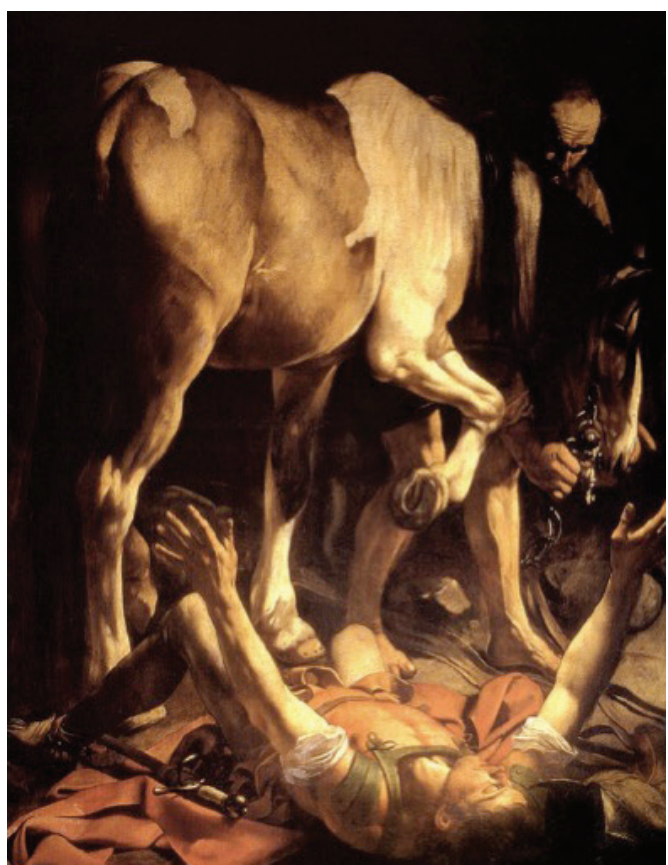

Fig. 4 - Caravaggio, a conversão de São Paulo. 1601

3.

"O que está acontecendo?"

O acontecimento não é um milagre que nos domina de admiração e nos fulmina. Ele nos eleva, precisamente porque é realizado por pessoas comuns que interrompem sua atividade habitual para agir coletivamente, dando poder não apenas àqueles que estão presentes, mas àqueles que, observando, sentem uma tremenda onda de solidariedade e senso de união humana, e mesmo (ouso dizer?) de universalidade. Testemunhamos a realidade de seres humanos se unindo para superar barreiras, para iniciar uma mudança. Essa capacidade de agir em comum é a possibilidade real de uma ética do comum.

A solidariedade produzida no espectador, tornada famosa por Kant no caso da Revolução Francesa, se intensificou na era eletrônica. Diferentemente da época de Kant e também 
de Lênin, foi a cobertura ao vivo pela televisão da ação política que inclinou a balança em favor da resistência não violenta. (O terror pode ser uma ferramenta política [Badiou], mas é um instrumento muito grosseiro, tão historicamente datado, talvez, como a bomba de hidrogênio [17]). Nos últimos anos, nos protestos eleitorais iranianos de 2009-2010, e durante as revoluções de jasmim da primavera árabe, o poder do protesto não-violento se multiplicou exponencialmente.

No caso de Kant, o caráter sangrento dos acontecimentos revolucionários franceses fez com que apenas a ideia lhe suscitasse entusiasmo. Na Praça Tahrir, era a realidade da força pacífica - a força da não-violência em face da violência [18], articulando um significado de martírio que tem implicações humanas universais. A revolução tecnológica dos dispositivos portáteis com acesso à internet proporcionou uma explosão de possibilidades para que as testemunhas oculares dos eventos ofereçam relatos de primeira mão. Transmitido em tempo real, o próprio relato se torna uma arma de resistência. Sem dúvida, a forma como as novas tecnologias são usadas depende das mãos que as manejam. Mas o que é notável é o quão confiável esse compartilhamento de informações tem sido. Certos agentes humanos assumiram a responsabilidade por outros de modo a arriscar sua própria segurança pessoal, liberando o que parece ser um desejo reprimido de trocar informações desinteressadamente, sem fins comerciais, e confiando que a comunidade internacional de telespectadores responderá em solidariedade - e eles o fazem [19]. (Afinal de contas, talvez sejamos animais socialistas por natureza).

No primeiro nível, então, "O que está acontecendo?" é uma questão empírica. Abordada a partir das atribuições de uma ética do comum, responder a essa questão requer, antes de mais nada, liberdade total de comunicação, para qualquer um que tenha conhecimento a compartilhar, com qualquer um que tenha o desejo de saber. Aqui, a divulgação de mídia independente, a coleta confiável de notícias e sua disseminação sem travas e sem filtros são projetos políticos da mais alta importância [20]. Quanto mais dispersos os pontos de observação, mais completo será o panorama dos acontecimentos [21]. 
Aliás, a vida de Steve Jobs é um exemplo dos benefícios da imigração para os EUA (seu pai era um muçulmano sírio, sua mãe era de ascendência alemã). Enquanto ele é elogiado como um herói da livre iniciativa, sua contribuição política crucial é o fato de que, desenvolvendo o computador pessoal, ele deu às pessoas o controle sobre os meios de produção da economia global - um ato do comum, se já houve um. As câmeras de vídeo dos telefones celulares mantêm à vista o protesto cidadão e a violência de Estado. Mas a Apple tira o poder do cidadão quando projeta o iPhone e iPad como plataformas visando lucros de renda, e quando essas formas diminuem a habilidade de uso do teclado, enfatizando a internet como um lugar de consumo, onde as ações dos usuários são monitoradas e vendidas como informação.

No segundo nível, o que está acontecendo é um ato de interpretação. Saber o que está acontecendo, para além da percepção sensorial virtualmente mediada (que, quando significa ver vídeos de brutalidade contra manifestantes desarmados, é o momento mais unanimemente e universalmente oposto ao acontecimento) é nomear a ação e situá-la em seu contexto. É aqui que começa, em seu nível mais básico, o difícil trabalho, muitas vezes conflituoso, de análise política. Como devemos chamar esse momento de ação cidadã? É democracia o que estamos testemunhando? Sim, com certeza. Mas, chamando-o assim, já parecemos sugerir a trajetória dos eventos: o sucesso significaria então a fundação de partidos políticos, a realização de eleições e a declaração de lealdade a um Estado-nação secular que atuaria segundo as regras pré-determinadas da ordem mundial estabelecida. Em outras palavras, aquilo que é subitamente possível em um acontecimento é seguir o exemplo das autoproclamadas democracias que já estão consolidadas. Mas nenhum desses passos decorre necessariamente do que aconteceu, o que, para as velhas e autoproclamadas democracias, é motivo de alarme. Os passos conhecidos, aqueles que elas deram, reduzem o significado do subitamente possível a um roteiro pré-escrito. Se, então, revisitarmos a questão - "O que há de novo?" - a resposta acaba sendo: não muito. 
Mas, e se a ação social iniciada em Túnis, Cairo e outros lugares for - enquanto acontecimento digno desse nome - uma estrutura política previamente inimaginável, não o modelo único e universal de democracia do Estado-nação - o qual, mesmo permitindo a diferença no interior de contextos culturalmente pluralistas, supõe que as formas euro-americanas, de dois séculos de idade (que atualmente estão respondendo mal às crises econômicas globais que suas instituições econômicas causaram) encarnam uma verdade eterna - mas um vislumbre da solidariedade global na qual as identidades nacionais e culturais são suspensas, e a unidade é a consequência, não de quem você é, mas sim do que você faz? Chamemos isto de uma prática do comum [22]. Todo o processo do ato de protesto e sua disseminação virtual é, em suas formas organizacionais horizontais, não-excludentes, uma manifestação brilhante de uma ética do comum, qualitativamente diferente, apontando para o poder subitamente possível da solidariedade global. Este é o novo que se revela neste acontecimento, um acontecimento que é menos uma ruptura do que uma abertura para alternativas ao estado de coisas dado.

A ideia aqui seria opor-se à definição de Schmitt e Agamben de soberano como aquele que decide em um estado de emergência, virando sua temporalidade e sua agência do avesso, e podemos fazer isso retornando ao significado do século XVI da palavra inglesa "emergency" como a condição do emergir [23]. O estado de emergência que produz uma crise para o soberano é uma possibilidade libertadora para os súditos, um momento para a "emergência" de uma nova situação, uma possibilidade de que a própria subjetividade possa ser transformada. 


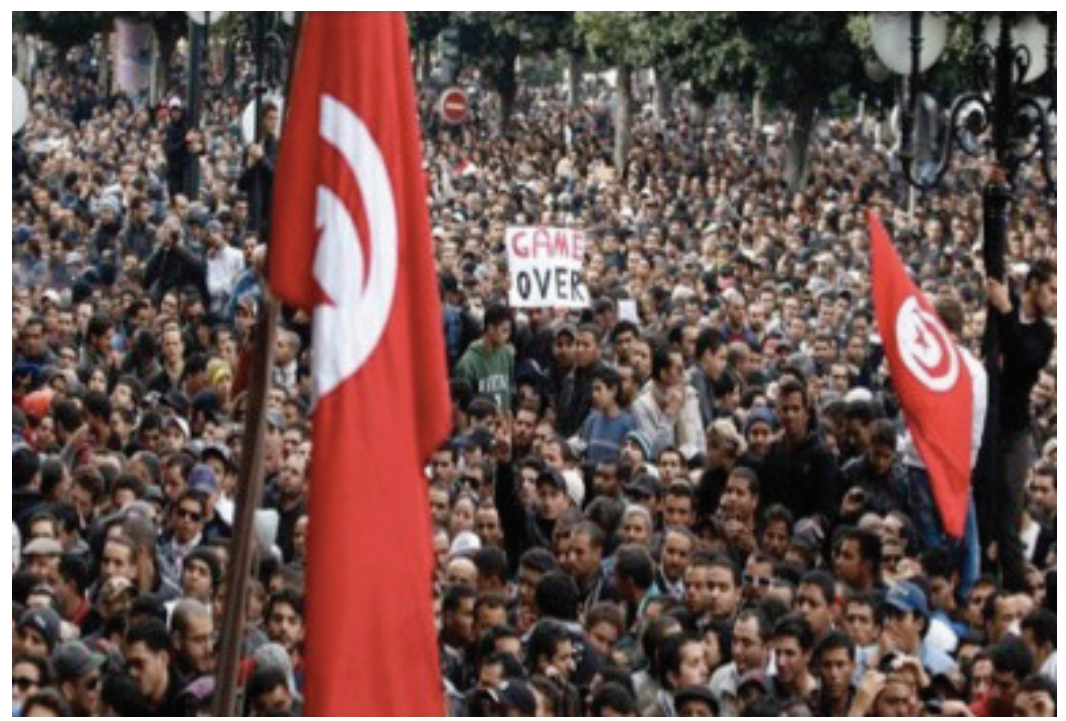

Fig. 5 - Tunísia, janeiro de 2011; http://www.pbs.org/ newshour/bb/international/jan-june11/tunisia2_01-17.html

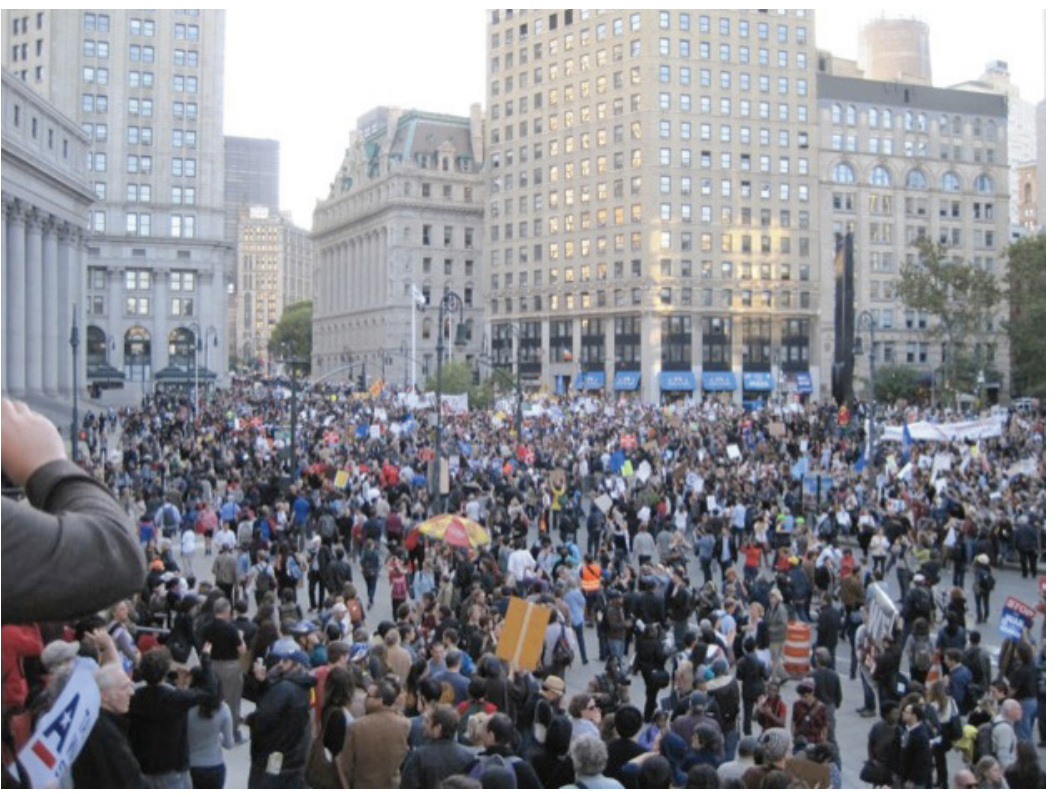

Fig. 6 - Ocupe Wall Street. Setembro de 2011 
Finalmente, em 28 de setembro de 2011, o New York Times trouxe para a grande mídia a maior história política do ano, reconhecendo oficialmente o que vinha acontecendo todo este tempo (Imagem 5 e 6). Uma reportagem de primeira página [24] reuniu as peças globais: A Primavera Árabe, o apoio na Índia à greve de fome de Anna Hazare, os protestos pró-justiça de cidadãos israelenses, os dias de tumultos em Atenas e Londres, os Indignados de la Republica na Espanha, bem como os acampamentos cidadãos dos "excluídos" que estão em curso nos espaços cívicos da Praça Tahrir até a Plaza del Sol e ao Parque Zuccotti. Precisamos acrescentar: a incrível bravura dos cidadãos na Síria, Iêmen e Bahrein que, sem ajuda da OTAN, persistem diante da violenta repressão dos governos, cuja legitimidade eles se recusam firmemente a reconhecer.

Primavera árabe, verão europeu, outono de Wall Street. Estamos testemunhando um movimento social global que afirma a diversidade e a universalidade, ambas de uma só vez. Claramente, é radical, recusando-se a aceitar as regras dadas do jogo. É uma virada para a esquerda? Talvez essa nomenclatura não possa mais ser usada - e esse fato é, também, o que é novo. Em nossa situação ciber-geográfica, as viradas à esquerda se posicionam de modo distinto sobre o terreno. Sua orientação é local e são necessariamente plurais. Isto, dentre muitas coisas, separa a ação do comum, global, do populismo de direita. Onde o último organiza a raiva contra a desordem global para apoiar ideologias rígidas de neo-nacionalismo, a privatização do livre mercado e políticas de anti-imigração, assim, cooptando movimentos de base em benefício dos partidos políticos existentes, por sua vez, a constelação trans-local de forças recusa-se a ser contida dentro dos limites do nacional ou do político. Para que "esquerda" e "direita" tenham algum sentido político, tem de haver fronteiras - fronteiras territoriais entre nações e fronteiras partidárias dentro delas. Os novos ativistas não estão dispostos a deixar-se seduzir pela retórica do "dividir para reinar". Eles são muito pouco práticos em sua ingenuidade? Isso é, afinal, um acontecimento? 


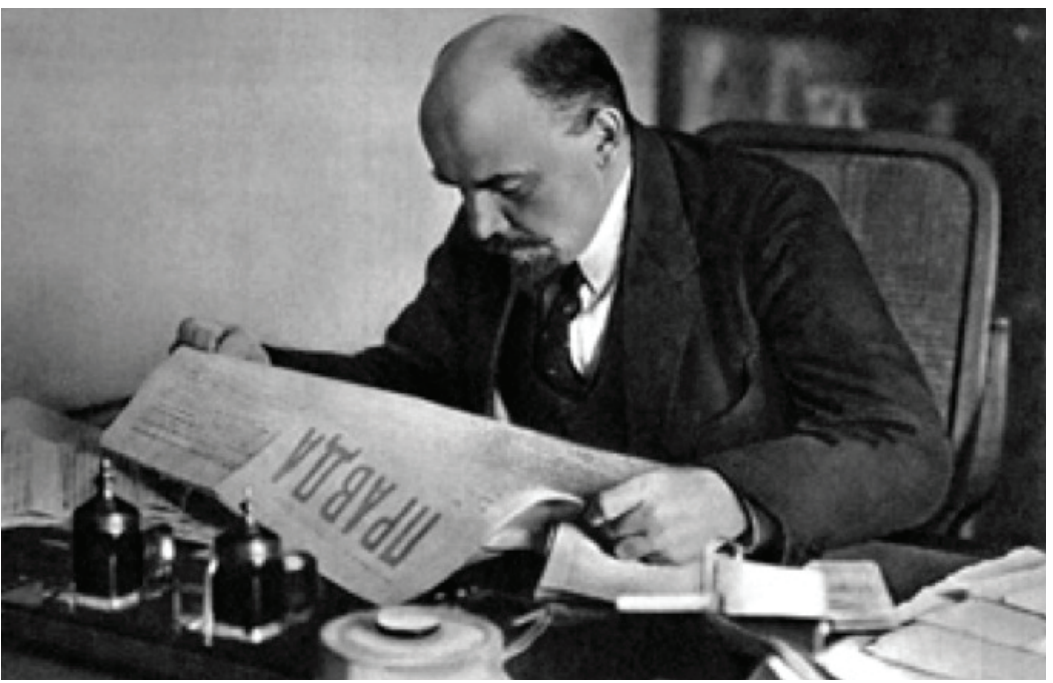

Fig. 7

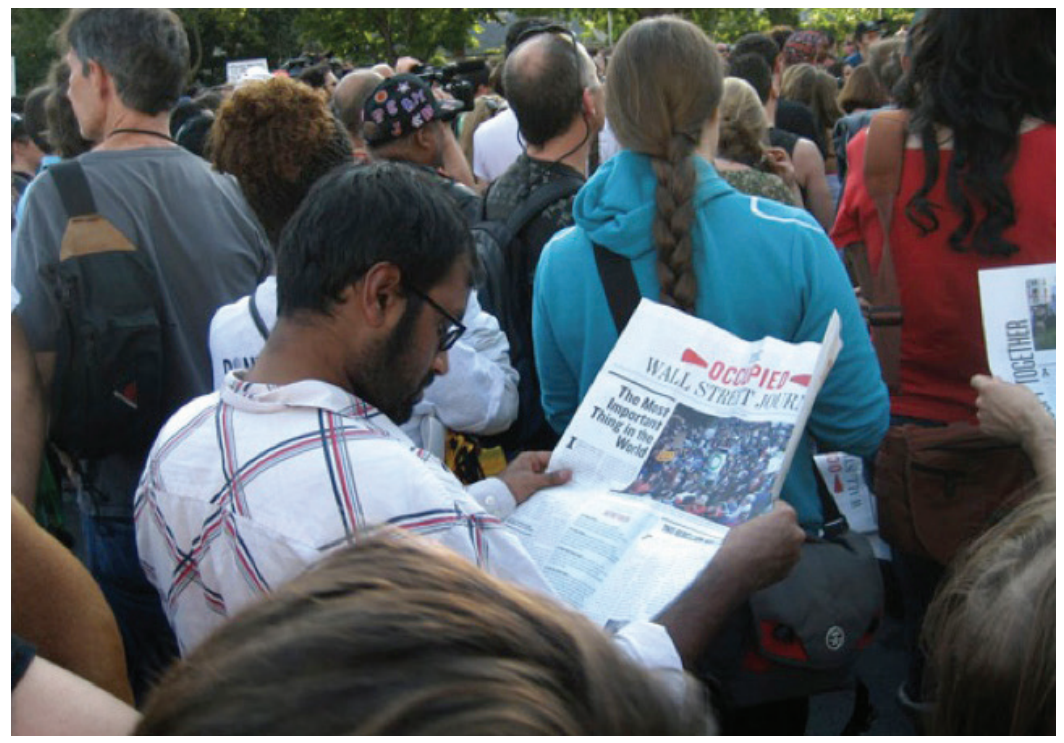

Fig. 8 - "A coisa mais importante do mundo" 
O que produz? Os muros caem, tiranos caem, um afro-americano, filho de imigrante, é eleito presidente dos Estados Unidos. Mas o que permanece? O que se mantém apesar de todas essas transformações? Os marxistas nos dirão: o sistema capitalista global. E a resposta não está errada. Quando Warren Buffett proclamou (dizendo a verdade a partir do poder): "Há, de fato, guerra de classes, e estamos vencendo", ele poderia ter acrescentado: "a nível mundial". Em tempos como o nosso hoje, em que estamos considerando um novo começo político, o elefante no meio da sala é o passado da política radical, sua dívida com a análise marxista do capital e com a ênfase desta na desigualdade econômica em uma teoria da exploração global da terra e do trabalho, na história dialética da luta de classes e na justificativa racional para a necessidade de uma revolução política para que a sociedade humana avance.

Nunca, ao longo de minha vida, a crítica marxista do capital e de sua dinâmica global pareceram mais precisas. E nunca pareceu mais errado voltar ao marxismo em suas formas históricas. Pelo menos durante a década de 1960, a teoria marxista era a língua franca dos ativistas em todo o mundo, não importando o quanto discordassem quanto à interpretação apropriada (soviética, trotskista, maoísta, humanista). A queda da União Soviética e a adoção de elementos capitalistas pela República da China deram um golpe fatal a essa convergência. Ao mesmo tempo, a teoria marxista não poderia resistir ao escrutínio da teoria feminista, pós-colonial, crítica da raça e outras teorias que estenderam o significado de opressão e exploração para muito além do que acontece no chão de fábrica. Em sua definição da universalidade humana, o marxismo foi provinciano na melhor das hipóteses. E sua lógica, muitas vezes determinista, estava firmemente ancorada em uma teoria dos estágios históricos que se mostrou simplesmente imprecisa graças a Samir Amin, Janet Abu-Lughod e Dipesh Chakrabarty, para citar alguns.

E a ideia do proletariado revolucionário? A classe trabalhadora, enquanto vanguarda política, ainda é a forma organi- 
zativa verdadeiramente relevante? Os sindicatos oficiais - nem todos, mas muitos e com muita frequência - atuaram como grupos incapazes de ir além das preocupações econômicas. É evidente que os protestos trabalhistas seguem tendo importância e oferecendo inovações. De Suez, no Egito, onde os sindicatos não-oficiais desempenharam um papel crucial de capacitação dos ativistas de Tahrir para bloquear o Canal de Suez, até Xintang, na China, onde trabalhadores emigrantes saíram às ruas para protestar contra a falta de direitos civis básicos que lhes eram negados, passando por Madison, em Wisconsin, onde mesmo o direito à negociação coletiva estava sendo ameaçado, ou pelos Conselhos de Trabalhadores e outros grupos trabalhistas que se uniram ao Occupy Wall Street como forma de apoio, as organizações de trabalhadores continuam desempenhando um papel crucial na luta [25]. Mas não apenas a maioria dos empregos hoje na maior parte do mundo não são sindicalizados. As razões pelas quais Marx argumentava a favor da importância fundamental da classe trabalhadora organizada podem talvez não mais se sustentar. A taxa salarial, entendida como "capital variável", deveria ser a parte da equação de custo do processo de produção que se prestava à pressão para baixo (em oposição ao capital fixo das máquinas), mas, como vimos, ela obedece a uma lógica diferente quando a produtividade elimina postos de trabalho. A Organização Internacional do Trabalho estima que o número de trabalhadores desempregados no mundo é de 200 milhões [26]. Uma pesquisa Gallop de janeiro de 2011 estabelecia que o desemprego mundial era de $7 \%$ da força de trabalho [27]. A geração mais jovem é a mais afetada. Atualmente, a juventude desempregada de todo o mundo teme menos fazer parte de um exército de reserva de mão-de-obra economicamente necessário do que ser economicamente desnecessária, uma população supérflua de seres humanos dispensáveis, permanentemente excluídos. E essa é uma resposta realmente assustadora (mas, ao mesmo tempo, dialeticamente poderosa [28]) à pergunta: o que há de novo?

Como as megalópoles do planeta evidenciam, realmente ocorreu uma proletarização massiva da força de trabalho. Mas as fábricas deixaram as cidades e se mudaram para outros 
enclaves. É impressionante o fato de que a força de trabalho migrante que elas empregam se mostrou notavelmente capaz de ação coletiva, apesar de sua posição precária e a despeito das diferenças étnicas e linguísticas [29]. E, no entanto, sua própria consciência cosmopolita permanece muito à frente do que foi alcançado por partidos políticos nacionalmente organizados.

Onde está a classe revolucionária? Esta pode ser a pergunta errada a se fazer. Talvez nenhuma das categorias - nem revolução nem classe - tenha em nosso tempo a força necessária. Primeiro: a transformação da sociedade está ainda vinculada à revolução no sentido clássico-moderno? Há muito tempo suspeito que a Revolução Iraniana de 1979 foi a última de uma longa tradição que chegou ao seu fim, seja na forma pró-nacionalista, anticolonialista, marxista ou teocrática. A instituição política do poder soberano por Khomeini, a Wilayat al-Faqih [Tutela dos juristas islâmicos], foi uma invenção pessoal, estranha não apenas às tradições ocidentais, mas também ao islamismo sunita e até mesmo ao pensamento político xiita. E ainda, o triunfo de Khomeini em uma guerra civil violenta tem afinidades com o protótipo revolucionário francês em muitas de suas características distintivas: fratricídio prolongado; dezenas de milhares de execuções políticas, incluindo as decapitações ritualísticas de inimigos políticos diante do público; uma trajetória de crescente radicalismo; um regime guiado pela ideia de virtude; uma reação termidoriana de centralização autoritária; e, finalmente, uma política externa girondina de expansão revolucionária. Mas se é possível espalhar a revolução proclamando seu triunfo para o mundo pelo Twitter, por que escolher o caminho da invasão em outros países?

Hoje, as decapitações gravadas em vídeo de vítimas aleatórias não têm o mesmo efeito que o regicídio cometido pela multidão de cidadãos da Place de la Révolution. Não é sentido pelo público global como vingança justificada. Como é o caso do bombardeio de civis, da demolição de casas e da tortura e humilhação de prisioneiros, ações consideradas desumanas e erradas. A abstração aqui opera dialeticamente: sem a linguagem legitimadora dos perpetradores, sem os significados 
contextuais predeterminados, a visão da violência contra vulneráveis evoca uma reação afetiva e visceral dos observadores globais que, precisamente porque a cena é retirada de contexto, respondem concretamente e com empatia. O fratricídio, a luta sangrenta da guerra civil como meio de transformação social, tem uma visão muito limitada, pois o processo de verdade e reconciliação que deve se seguir revela-se extremamente difícil. $\mathrm{E}$, como as reações termidorianas deixam claro, é muito mais fácil esmagar a velha ordem do que construir uma nova.

Isto no que se refere à revolução violenta. Mas a categoria de classe social realmente se tornou obsoleta? O elefante no meio da sala ainda está conosco: a verdade é que, no mundo do capitalismo global, praticamente em toda parte do tabuleiro geopolítico, os ricos continuam ficando mais ricos e os pobres cada vez mais pobres - e os que estão no poder, longe de protestar, nos dizem que este sistema precisa de uma maior e especial proteção, muito maior do que a dada aos próprios cidadãos. Os livres mercados (acumulação capitalista descontrolada) e sociedades livres (democracias de estilo ocidental) uniram-se e o produto final é a oligarquia global. A chamada comunidade das nações protege um sistema global de cercamentos, que funciona para se apropriar de todo valor de uso que pode ser transformado em um empreendimento lucrativo. Nada - nem escolas, nem prisões, nem genes humanos, nem plantas selvagens, nem o exército nacional, nem governos estrangeiros - nada está imune a este processo de privatização.

Então, há luta de classes sendo travada, de cima para baixo. Mas há guerra de classes? Somente se o resto do mundo, os 99\% de nós, responder à altura. (Mesmo Warren Buffett não está feliz com o papel que ele deveria desempenhar). Quero opor-me à ideia de que todo o objetivo da política é nomear o inimigo (a distinção amigo / inimigo de Schmitt) e estruturar nossa organização política de uma maneira instrumental em vista da derrota do inimigo.

A política agonística é uma relação social mutuamente dependente. Ambos os lados devem jogar o jogo. Talvez não houvesse nada mais propício aos conservadores do que identifi- 
car nossa resistência à ordem capitalista, neoliberal, nos termos tradicionais e limitados da guerra de classe. Talvez nada deixaria as autoridades mais aliviadas do que se o Occupy Wall Street se tornasse um movimento violento, porque o Estado poderia então justificar o uso da violência policial para derrubá-lo. Mas o poder da grande maioria, dos 99\%, reside simplesmente na grandeza numérica e não requer conflito armado para provar seu ponto. E esse ponto é: o sistema de que dependemos, o sistema que está incorporando cada vez mais e mais de nosso mundo, não está apenas fora de controle, mas é punitivo, irracional e imoral ou, nas palavras de Badiou, brutal e bárbaro.

Uma comunidade mundial de Estados-nação democráticos e soberanos supostamente deveria ser o fim da história, não o fim da humanidade. Mas o que devemos fazer do nosso mundo, baseado em contradições absurdas, em que o parlamento democraticamente eleito da Grécia tributa o povo até a miséria a fim de salvar a nação? Ou a nação do Iraque que é libertada por meio da destruição de sua infraestrutura e da morte ou deslocamento de $20 \%$ da população? A lógica tem de fato algo fundamental em comum com a da Guerra Fria, quando a capacidade de destruir a vida no planeta era o padrão ouro da segurança militar, e quando as aldeias pós-coloniais no Vietnã eram completamente bombardeadas para salvar seus habitantes do comunismo.

Isso é um comportamento social aceitável e é uma loucura! Uma ética do comum exige que digamos isso. A chamada livre escolha dos eleitores cidadãos não é liberdade e não é uma escolha [30]. A tese de Weber é distorcida em uma nova tautologia: o Estado capitalista produz o espírito do capitalismo objetivado que reproduz a ética capitalista, em um eterno retorno do mesmo.

\section{5.}

O brilho de otimismo sentido em todo o mundo quando Barack Obama conquistou a presidência dos EUA em 2008 foi a última (e perdida) chance de acreditar que o sistema era capaz 
de se endireitar. A lealdade de Obama aos dois pilares da ordem mundial - economia capitalista e interesse próprio nacional - demonstrou em sua presidência a falência de ambos. Uma vez que os livres mercados em uma sociedade livre falharam em suprir as necessidades humanas básicas, podemos pedir aos cidadãos do mundo que voltem a ter esperança novamente? É claro que a analogia é exagerada, e a emergência política é qualitativamente diferente - Obama, felizmente, não é fascista e, infelizmente, não é socialista o suficiente - mas podemos lembrar de um diálogo entre Albert Speer e Adolf Hitler em março de 1945, enquanto o exército soviético se aproximava de Berlim. Hitler ficou furioso ao descobrir que Speer havia obstruído suas ordens, mas então se acalmou e disse "em um tom relaxado":

"Speer, se você puder se convencer de que a guerra não está perdida, você pode continuar a administrar seu escritório..." "Você sabe que não posso ser convencido disso", respondi sinceramente, mas sem provocação. "A guerra está perdida."

Hitler se entregou a suas reflexões [...] sobre outras situações difíceis de sua vida, situações em que tudo parecia perdido, mas que tinha conseguido superar [...] Surpreendentemente rebaixou suas exigências: "Se você acreditasse que a guerra ainda pode ser vencida, se você pudesse ao menos ter fé nisso, tudo estaria bem [...."

Agitado, [...] eu disse: "Eu não posso, nem com a melhor boa vontade do mundo [...]" Uma vez mais, Hitler reduziu suas exigências a uma profissão formal de fé: "Se pelo menos você pudesse ter a esperança de que não perdemos! Você certamente deve ser capaz de ter esperança [...] isso seria o suficiente para me satisfazer."

Eu não respondi.

Houve uma longa e embaraçosa pausa. Por fim, Hitler levantou-se abruptamente [...] "Vocề tem vinte e quatro horas para pensar na sua resposta! Amanhã, deixe-me saber se você tem esperança de que a guerra ainda possa ser vencida". Sem apertar as mãos, ele me dispensou [31].

Insisto que a comparação não se refere à liderança. É apenas para ressaltar que a esperança também pode ser uma ideologia. Não posso deixar de sentir que o próprio Obama está ciente desse perigo, certamente tendo acreditado no processo democrático que o levou à vitória eleitoral há tão pouco tempo. Obama gostava de repetir: "isso não é sobre mim". E estava 
absolutamente certo. Não era. Porém faltava a ele mesmo fé nas pessoas que o elegeram. Obama tem orgulho de se chamar um pragmático. Ele apenas esqueceu uma coisa: ao tentar ser realista dentro dos limites do enlouquecido status quo, ele traiu a pragmática do subitamente possível, que é, afinal de contas, a força que antes de tudo o elegeu. Esta força é global e anseia desesperadamente por uma mudança. É a única força política sensata que o mundo tem atualmente.

Neste momento, ser pragmático no sentido de ser cauteloso, procedendo razoavelmente no interior do todo irracional, é o caminho verdadeiramente arriscado. Os líderes mundiais reconhecerão isto? Eles vão acordar para o fato de que o sistema sobre o qual se apoiam está falido, e que seu poder se assenta no ar?

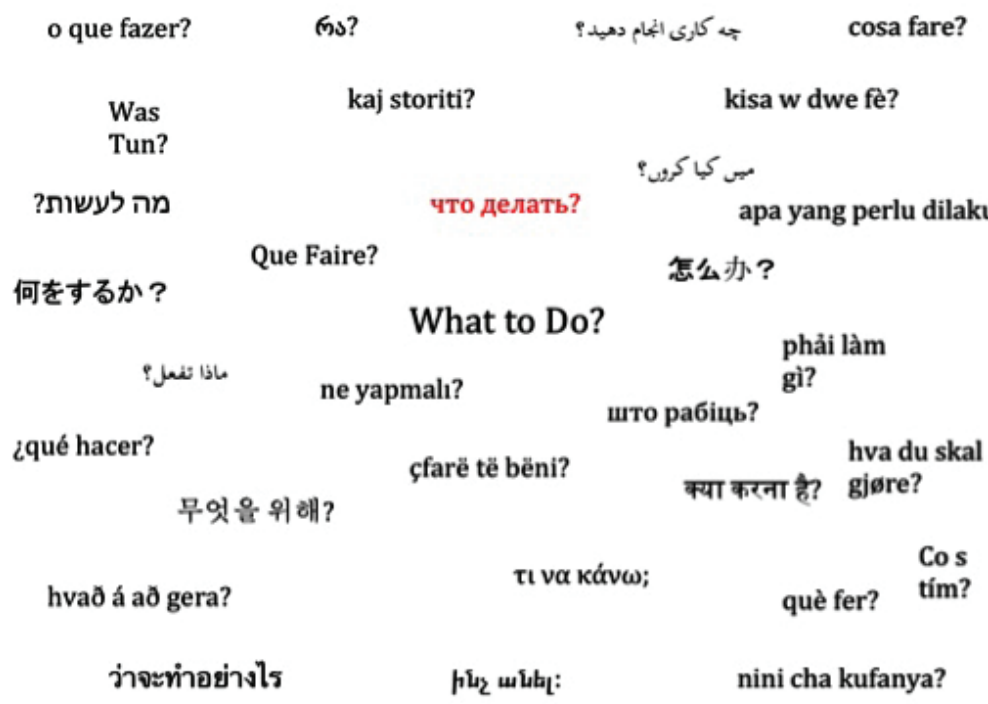

Fig. 9 - O que fazer? 


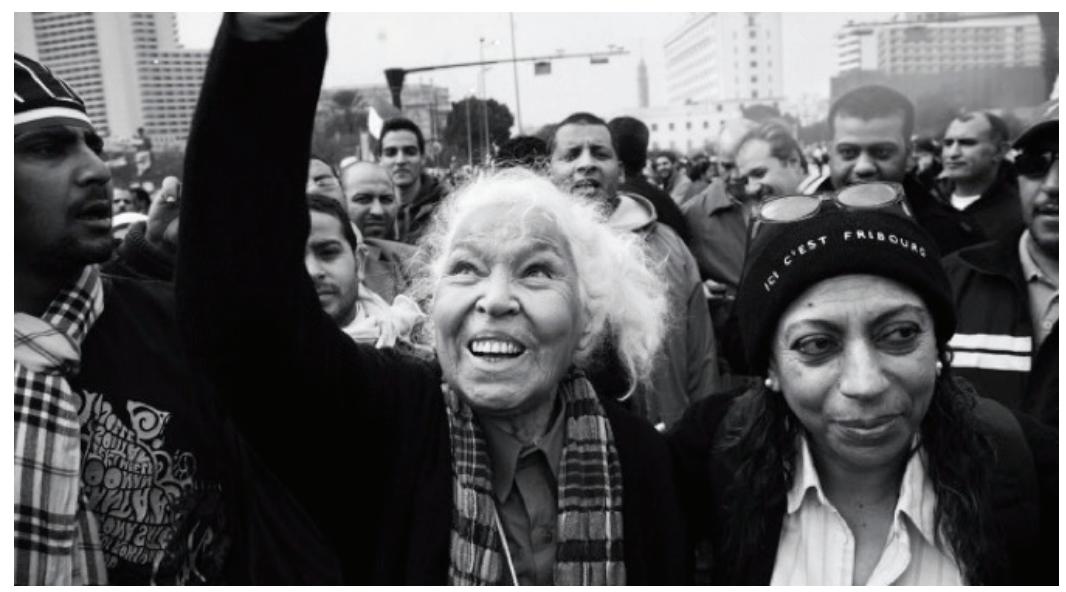

Fig. 10 - Nawal Sadaawi, Feminista Egípcia, na Praça Tahrir, Cairo. Primavera de 2011

Convém repetir as palavras que a feminista egípcia Nawal Sadaawi pronunciou na primavera passada: faça sua própria revolução. Os caminhos a seguir serão tão variados quanto as pessoas deste mundo. As feministas, globalmente, nos têm ensinado a necessidade de tal diversidade [32]. Todos esses caminhos adiante merecem nossa solidariedade e apoio. Nós, os $99 \%$, devemos recusar a nos tornar invisíveis um ao outro. Os experimentos que estão ocorrendo agora em milhares de lugares precisam de espaço, o espaço que Walter Benjamin chamou de Spielraum (espaço de jogo) para tentar fazer as coisas de maneira diferente. E eles precisam de tempo, da desaceleração do tempo, de puxar o freio de emergência, para que algo novo possa emergir. Um tempo que o poder estatal quer abreviar, e um espaço que os velhos partidos políticos querem excluir.

Não há pressa. A desaceleração do tempo é ela mesma o novo começo [33]. A cada dia que este acontecimento segue adiante, realiza-se a possibilidade de que o mundo possa ser diferente. Contra a hegemonia da atual ordem mundial que se apresenta como natural e necessária, os atores globais estão abrindo um buraco no conhecimento. Novas formas emergem. Elas alimentam nossa imaginação, o poder mais radical que nós, como humanos, temos. 


\section{Notas}

[1] Bruno Bosteels cita Mouffe em "The Ontological Turn" [A virada ontológica], em seu informativo novo livro The Actuality of Communism [A atualidade do comunismo] (Londres/Nova York: Verso, 20011), pp. 40-41. Mouffe: "[...] é a falta de compreensão do 'político' em sua dimensão ontológica que está na origem de nossa atual incapacidade de pensar de maneira política" (Chantal Mouffe, On the Political [Nova York: Routledge, 2005], p 80. Também Negri: "Aqui é onde o comunismo precisa de Marx: para instalar-se no comum, na ontologia, e vice-versa: sem ontologia histórica não há comunismo" (Antonio Negri, "Est-il possible d'être communiste sans Marx?" [E possível ser comunista sem Marx?] citado em Bosteels, "The Ontological Turn", p. 49.)

[2] Para uma exame crítico da ontologia de esquerda, ver Carsten Strathausen, ed., A Leftist Ontology: Beyond Relativism and Identity Politics [Uma ontologia de esquerda: para além do relativismo e das políticas identitárias] (Minneapolis: University of Minnesota Press, 2009), particularmente o "Afterward" conclusivo de Bruno Bosteels (reimpresso como "The Ontological Turn" [A virada ontológica], citado acima)

[3] "On Evil: An Interview with Alain Badiou," [Sobre o mal: uma entrevista com Alain Badiou] Cabinet 5 (2001/02), em: http:// www.cabinetmagazine.org/issues/5/alainbadiou.php

[4] Para a ontologia pós-metafísica, a essência não pode ser uma categoria transcendente, mas deve permanecer imanente à existência. Como Heidegger escreve: “a 'essência' [Wesen] desta entidade está em seu 'ser"' (Martin Heidegger, Being and Time [Ser e tempo], trad. John Macquarrie e Edward Robinson [Nova York: Harper \& Row, 1962), p. 67; Original alemão, p. 42). O ser referido aqui (ser com um "s" minúsculo) é o mundo "dado", o mundo que "es gibt" (que "há") enquanto o ser humano, consciente, é ontologicamente entendido como "Dasein" ("ser-aî").

[5] Cf. O método de redução fenomenológica de Husserl que influenciou Adorno quando estudante.

[6] No nível do ôntico, o verbo "é" é usado descritivamente e a verdade é uma questão de percepção acurada, portanto, basicamente um problema epistemológico. Mas outra coisa é supor, mergulhando nas estruturas do ôntico, que elas próprias são capazes de revelar uma verdade ontológica mais profunda. Se uma tal "diferença ontológica" é impossível, como afirmou Adorno, então todo o procedimento é uma farsa.

[7] Adorno criticava o conceito liberal-parlamentar de compromisso, como fez Schmitt, mas precisamente pela razão oposta, ou seja, porque as diferenças de posição não eram grandes o bastante. $\mathrm{O}$ princípio de não-identidade de Adorno - sua afirmação de que a verdade não está na segura equidistância, mas que, em vez disso, 
les extrèmes se touchent [os extremos se tocam] - poderia ser politicamente interpretado como um meio intransigente a serviço do fim democrático.

[8] "A analítica existencial do Dasein [Ser com S maiúsculo] vem antes de qualquer psicologia ou antropologia, e certamente antes de qualquer biologia" - isto é, antes dos corpos materiais dos seres humanos reais!" (Heidegger, Being and Time [Ser e tempo], p. 71; Alemão, p, 45). Ou, em outro exemplo, ferramentas são meros "seres-a-mão" e seu exemplo é a caneta com a qual ele escreve. Se a análise ontológica precede o conhecimento ôntico, não há como a descrição ontológica diferenciar entre as ferramentas-à-mão do filósofo e aquelas de um trabalhador em uma linha de montagem (Being and Time, pp. 95-102; Alemão, pp. 67-72). Ou, sobre a relação entre filosofia e ciências sociais: "Devemos sempre ter em mente que as fundações ontológicas nunca podem ser reveladas por hipóteses posteriores derivadas de material empírico, mas que elas sempre já são "aí", mesmo quando esse material empírico é simplesmente coletado" (Being and Time, p. 75; Alemão, p. 50).

[9] Robert C. Tucker, The Marx-Engels Reader [O livro de leitura Marx-Engels, 2nd ed. (New York: W. W. Norton \& Company, 1978), p. 86 (Karl Marx, Manuscritos Econômico-Filosóficos. São Paulo: Boitempo, 2004, p. 107). O original alemão é:

"Allein auch wenn ich wissenschaftlich etc. tätig bin, eine Tätigkeit, die ich selten in unmittelbarer Gemeinschaft mit andern ausführen kann, so bin ich gesellschaftlich, weil als Mensch [ital. Mine] tätig. Nicht nur das Material meiner Tätigkeit ist mir - wie selbst die Sprache, in der der Denker tätig ist - als gesellschaftliches Produkt gegeben, mein eignes Dasein ist gesellschaftliche Tätigkeit; darum das, was ich aus mir mache, ich aus mir für die Gesellschaft mache und mit dem Bewußtsein meiner als eines gesellschaftlichen Wesens."

[10] Agradeço ao iraniano Ahmad Jalali por questionar gentilmente minha escolha de título para o meu livro, Thinking Past Terror: Islamism and Critical Theory on the Left [Pensando para além do terror: islamismo e teoria crítica na esquerda], precisamente nesses termos.

[11] Cf. A insistência de Adorno na prioridade do objeto (Vorrang des Objekts).

[12] Soyinka, citado em Michael Richardson, Refusal of the Shadow, Surrealism and the Caribbean [Recusa da sombra, surrealismo e o Caribe] (Londres: Verso, 1996), p. 10.

[13] É claro que Achille Mbembe está absolutamente certo em apontar que a nègritude não era uma filosofia de primeiros princípios, mas uma prática política completamente engajada. Temos que reconhecer que os escritores que teorizaram a negritude estavam engajados em uma pragmática de contra-hegemonia com efeitos institucionais e políticos reais (Achille Mbembe, seminário, Committee on Globalization and Social Theory, CUNY Graduate Center, setembro de 2011). Ver também Ngugi wa Thiong'o, Globalectics: Theory and 
the Politics of Knowing [Globaléticas: teoria e política do conhecer] (Nova York: Columbia University Press, 2012), p. 23

[14] Ver o livro de Lars T Lih, Lenin Rediscovered: What is to Be Done? In Context [O que é para ser feito? Em contexto] (Chicago: Haymarket Books, 2008) sobre sua confiança nos trabalhadores, especialmente os social-democratas alemães, quando ele escreveu este panfleto. Muitos defenderam que a Revolução Russa chegou cedo demais e, portanto, fracassou. Talvez, em vez disso, os primeiros anos da revolução bolchevique sejam os mais relevantes, já que suas práticas nunca deixaram de servir de inspiração: a estética vanguardista, o teatro de rua, os trens da agitprop, a greve geral mundial de 1919 que foi um dos primeiros atos, em grande medida espontâneos, de solidariedade global. Nos Estados Unidos, Eugene V. Debs respondeu à vitória de Lenin, exclamando: "Do topo da minha cabeça até o fundo dos meus sapatos, eu sou um bolchevique e tenho orgulho disso!" Em 1920, ele concorreu à presidência da prisão como o candidato do partido socialista e ganhou um milhão de votos. O jornalista Victor Berger postou em outdoors: "A guerra é o inferno causado pelo capitalismo" - e foi eleito o primeiro candidato socialista para o Congresso dos EUA. Condenado, como Debs, sob o Ato de Espionagem, foi-lhe negado o assento do Congresso para o qual ele havia sido eleito duas vezes pelo eleitorado.

[15] V. I. Lenin, citado em Robin Blackburn, ed., After the Fall: The Failure of Communism and the Future of Socialism [Depois da queda: o fracasso do comunismo e o futuro do socialismo] (New York: Verson, 1991), p. 167.

[16] Alain Badiou, Being and Event [Ser e evento], trad. Oliver Feltham (New York: Continuum, 2005).

[17] Badiou sobre o que deve ser feito: "[...] o uso do terror em circunstâncias revolucionárias ou em guerra civil não significa de modo algum que os líderes e militantes sejam insanos, ou que expressem a possibilidade de um Mal interno. O terror é uma ferramenta política que tem sido usada desde quando existiram sociedades humanas. Deve, portanto, ser julgado como um instrumento político, e não submetido a um julgamento moral infantilizador. Deve-se acrescentar que existem diferentes tipos de terror. Nossos países liberais sabem como usá-lo perfeitamente".

Ver o vídeo desta palestra ("Alain Badiou. Philosophy: What Is to Be Done?", 2010) em https://www.youtube.com/watch?v=kBzp0PZKtwc. [Seu texto para esta conferência esclarece que a violência não é uma condição necessária à ideia comunista.]

[18] Não violência [Gewalt] mas força [Kraft], como o termo é usado por Hegel na Lógica da Enciclopédia, parágrafo 136.

[19] Em contraste, no caso iraniano, a corporação (finlandesa-alemã) Nokia pôs a consciência política de lado para trabalhar com o governo iraniano em vista do bloqueio da comunicação por internet dos manifestantes. 
[20] Os efeitos da regulamentação governamental já foram sentidos na China, onde o governo bloqueou o Facebook e o Twitter como prejudiciais ao "interesse nacional chinês". O Google recusou-se a obedecer e transferiu suas torres para Hong Kong, deixando espaço para o mecanismo de busca doméstico chinês [Baidu] expandir. A regulamentação das fronteiras nacionais virtuais produz uma guerra comercial global pela informação. (ver o trabalho de Ying Zhu e o filme "Google vs. China").

[21] Não me surpreende a idolatria a figuras como Julian Paul Assange, que ganhou status de celebridade, e talvez outros prazeres narcísicos, pelo simples fato de ter vazado uma grande quantidade de documentos privados. Dizer que sua disseminação de documentos do Pentágono desencadeou a revolução na Tunísia é como dar crédito a Ronald Reagan pela queda do Muro de Berlim. É muito mais provável que tais atos sirvam no plano político como desculpa para que governos auto-denominados democráticos implementem um controle sobre a internet (o que significa que, independentemente de seus motivos pessoais, Assange precisa ser defendido neste caso).

[22] Se quisermos encontrar um precedente em Hegel, seria seu comentário na Lógica da Enciclopédia de que as pessoas devem ser julgadas não por seus motivos, mas por suas ações: "Aqui, também, a unidade essencial de interior e exterior segue sendo válida; e, portanto, deve-se dizer que uma pessoa é o que faz". Nesta mesma seção, ele critica o que foi então chamado de "historiografia pragmática", referindo-se (diferente de nosso uso aqui de "pragmático") àqueles que descreditam a ideia de que os agentes históricos são motivados por algo diferente de sua vaidade pessoal, fraquezas, e etc. Hegel sustenta que a essência interior de alguém aparece em suas ações: "Deve ser reconhecido que os grandes homens desejaram o que fizeram e fizeram o que desejaram". Não é preciso adotar sua teoria da história do Grande Homem para defender, no entanto, que a ação coletiva, consciente de si, nos inspira precisamente porque evidencia a possibilidade humana de superar os interesses pessoais no interior do bem coletivo. De fato, a reflexão crítica nos diz que o que a sociedade alega ser de nosso interesse próprio é, de fato, sempre mediado pelos interesses dos outros - e é, em sua forma presente e individualista, profundamente alienante. (Ver Hegel, Lógica da Enciclopédia, parágrafo 140).

[23] Esta conexão linguística não funciona em alemão (emergência = Entstehung), mas outra conexão funciona. O que para o soberano é um súbito estado de emergência (em alemão, Notstand), é, para os súditos, uma ruptura de sua experiência cotidiana da precariedade existencial e da pobreza (em alemão, Not). Enquanto o soberano reage à crise com alta velocidade e poder ditatorial - não há tempo para sutilezas jurídicas - os súditos do soberano não precisam se mover rapidamente; eles exigem tempo para a mudança emergir. Para usar a imagem de Walter Benjamin, talvez a revolução não seja, 
pace Marx, a locomotiva da história, mas a tentativa da humanidade de puxar os freios de emergência (Notbremse) deste trem.

[24] Por Nicholas Kulish (com seus colegas Ethan Bronner em Tel Aviv e Jim Yardley em Nova Delhi). Os protestos chineses em Lufeng são de um artigo posterior de Andrew Jacobs, com contribuição de Ia Li, em 24 de setembro de 2011.

[25] É impressionante como aqueles no poder tinham consciência das conexões dos protestos trans-locais de 2011:

"O representante de Wisconsin Paul Ryan, uma estrela em ascensão no Partido Republicano, igualou na quinta-feira os protestos contra o plano de orçamento do governador de seu estado Scott Walker às manifestaçõ̃es históricas no Egito que na semana passada levaram à queda do presidente Hosni Mubarak. "Está ficando tumultuado. É como se nestes dias Cairo tivesse se mudado para Madison", disse Ryan em "Morning Joe", da MSNBC (Disponível em http://www.rawstory.com/rs/2011/02/17/ wisconsin-labor-protests-like-cairo-gops-paul).

No caso de Xintang: "A restrição de segurança este ano também é geralmente atribuída aos protestos que agitam o Oriente Médio e o Norte da África, algo que as autoridades chinesas não querem que se imite em seu país" (Disponível em http: //www.pbs. org / newshour / rundown / 2011/07 / china-protests.html). Para o significado dos sindicatos não oficiais de Suez na primavera do Egito, ver "Striking Suez Unions fuel the Uprising after 10 Years of Labor Organizing" [Sindicatos em greve de Suez alimentam a revolta depois de 10 anos de organização trabalhista] (Disponível em http://www.democracynow.org/2011/2/10/egyptianuprisingsurgesasworkers_join).

[26] Ver a reportagem da ONU sobre o desempre-

go (Disponível em http://www.un.org/apps/news/story. asp? NewsID $=37370 \& \mathrm{Cr}=$ unemployment $\& \mathrm{Cr} 1$ ).

[27] Isto de acordo com o Los Angeles Times, 19 de janeiro de 2011, "Worldwide unemployment is about 7\%, new Gallup survey finds"

[Nova pesquisa de Galup revela que desemprego mundial é de aproximadamente 7\%] (Disponível em http://latimesblogs.latimes.com/ money_co/2011/01/worldwide-unemployment-is-about-7-new-gallup-survey-finds.html).

[28] Žižek está absolutamente correto em apontar isso: "Quando essa lógica chega ao seu extremo, não seria razoável levá-la à sua autonegação: um sistema que torna irrelevantes e inụ́teis $80 \%$ das pessoas não é ele mesmo irrelevante e inútil?", Slavoj Žižek, First as Tragedy, Then as Farce [Primeiro como tragédia, depois como farsa] (Londres: Verso, 2009), p. 103.

[29] Ver Paul Apostolidis, Breaks in the Chain: What Immigrant Workers Can Teach America about Democracy [Quebras na corrente: o que trabalhadores imigrantes podem ensinar à América sobre democracia] (Minneapolis: University of Minnesota Press, 2010). 
[30] Neste ponto se mostra pertinente a crítica de Hegel: a identificação que a democracia liberal faz entre liberdade de escolha e liberdade formal implica, portanto, em "uma liberdade que não o é em absoluto" (ver Hegel, Lógica da Enciclopédia, parágrafo 145).

[31] A. Speer, citado em Nicholas H. Smith: "Peter Dews, The Idea of Evil" [A ideia do mal] resenha do livro em Critical Horizons 9:1 (2008), p. 13.

[32] Ver Zillah Eisenstein e Chandra Mohanty, "In Support of Occupy Wall Street [Em apoio ao Occupy Wall Street]" Feminist Wire, postado em 14 de outubro de 2011 (Disponível em http://thefeministwire.com/2011/10/in-support-of-occupy-wall-street/)

[33] A crítica de Badiou ao tempo capitalista em "The Communist Idea and the Question of Terror" [A ideia comunista e a questão do terror], em The Idea of Communism [A ideia de comunismo] Volume 2 (Londres: Verso, 2013) vai direto ao ponto aqui. 